\title{
Microarray gene expression analysis in ovine ductus arteriosus during fetal development and birth transition
}

\author{
Ravi Goyal', Dipali Goyal', Lawrence D. Longo' and Ronald I. Clyman²
}

BACKGROUND: Patent ductus arteriosus (PDA) in the newborn is the most common congenital heart anomaly and is significantly more common in preterm infants. Contemporary pharmacological treatment is effective in only $70-80 \%$ of the cases. Moreover, indomethacin or ibuprofen, which are used to close a PDA may be accompanied by serious side effects in premature infants. To explore the novel molecular pathways, which may be involved in the maturation and closure of the ductus arteriosus (DA), we used fetal and neonatal sheep to test the hypothesis that maturational development of DA is associated with significant alterations in specific mRNA expression.

METHODS: We conducted oligonucleotide microarray experiments on the isolated mRNA from DA and ascending aorta from three study groups (premature fetus $-97 \pm 0 \mathrm{~d}$, near-term fetus $-136 \pm 0.8 \mathrm{~d}$, and newborn lamb-12 $\pm 0 \mathrm{~h}$ ). We compared the alterations in mRNA expression in DA and aorta to identify genes specifically involved in DA maturation.

RESULTS: Results demonstrate significant changes in wingless-integrin1, thrombospondin 1, receptor activator of nuclear factor-kappa B, nitric oxide synthase, and retinoic acid receptor activation signaling pathways.

CONCLUSION: We conclude that these pathways may play an important role during both development and postnatal DA closure and warrant further investigation.

$\mathrm{T}$ he ductus arteriosus (DA) represents a persistence of the terminal portion of the sixth brachial arch. During fetal life, the DA serves to divert blood away from the fluid-filled lungs toward the descending aorta and placenta. After birth, constriction of the DA and obliteration of its lumen separate the pulmonary and systemic circulations. In full-term infants, obliteration of the DA takes place during the first $72 \mathrm{~h}$ after birth through a process of vasoconstriction and anatomic remodeling of ductus intima and media resulting in its permanent closure (1).

In contrast with the full-term newborn, in the preterm newborn the DA frequently fails to close. This is due to the preterm ductus' limited ability both to actively vasoconstrict and reduce its luminal flow, as well as its limited ability to remodel its intimal/medial wall (1). When a patent ductus arteriosus
(PDA) persists after birth, the blood shunts from the highpressure aorta to the low-pressure pulmonary artery (left to right shunt). This can lead to pulmonary hyperemia and edema and decreases renal, mesenteric, and cerebral perfusion resulting in pulmonary engorgement with an increase in pulmonary vascular resistance and congestive cardiac failure. In those cases in which the pulmonary vascular resistance exceeds the systemic vascular resistance, the blood shunts from right to left. The main therapeutic option for a PDA is to treat the neonate with indomethacin or ibuprofen to inhibit the enzyme cyclooxygenase and thus inhibit prostaglandin synthesis. This is successful in about $70-80 \%$ of infants. Its use, however, may lead to undesirable side effects such as gastrointestinal bleeding, perforation, and/or necrotizing enterocolitis. If the PDA does not close by the age of 1-2 y, an operative closure (ligation or plug) is the only option for these infants. In full-term neonates, persistent PDA occurs in about 8 of 1,000 live births and makes up $5-10 \%$ of all congenital heart defects. Among preterm infants, the incidence of persistent PDA at the end of the first year is a several-fold higher.

At present the genes specific to the DA's developmental maturation in utero and associated with its postnatal anatomic closure are not known. Therefore, we tested the hypothesis that DA developmental transition is associated with differential gene expression. The aim of our study was to identify those genes and gene pathways that are altered during both developmental transitions (fetal maturation and postnatal closure) and whose alterations are unique to the DA. We examined gene expression profiles in DA and ascending aorta from premature fetal, near-term fetal, and newborn lambs using oligonucleotide microarray analysis. We compared the differential gene expression between the DA and ascending aorta to identify genes that are altered as a consequence of generalized vascular development and to differentiate them from genes specific for maturation of the DA.

\section{RESULTS \\ Quality Check of Microarray Experiment \\ RNA purity of the study samples was between 1.8 and 2.0 ratio of $\mathrm{OD}_{260 / 280}$ as determined by UV spectrophotometry. Further quality of RNA was checked by Agilent Bioanalyzer (see Supplementary}


Figure $\mathbf{S 1}$ online), and the RNA integrity numbers were between 8.5 and 10. The RNA samples then were converted to cRNA targets and analyzed on Agilent Bioanalyzer. The electropherogram profiles (see Supplementary Figure S2 online) demonstrate high-quality cRNA. Intensity normalization was conducted following log transformation, and the probes above background were included in further analysis (see Supplementary Figure S3 online). Real-time PCR validation demonstrated that the foldchanges of the 12 genes examined were within 2 SDs of the values obtained by microarray experiment.

\section{Developmental Changes in Gene Expression in DA and Aorta}

To examine the genes exclusively regulated in DA during development and after birth, we compared the differences in gene expression (in the DA and aorta) between $97 \pm 0 \mathrm{~d}$ and $136 \pm 0.8 \mathrm{~d}$ gestational age fetuses, as well as between $136 \pm 0.8 \mathrm{~d}$ gestation fetuses and newborn lambs $(12 \pm 0 \mathrm{~h})$. Figure 1 presents the Venn diagrams of the genes that are differentially expressed in the three comparison groups from the DA (Figure 1a) and aorta (Figure 1b). As shown in the figure, with maturation of the fetus from $97 \pm 0$ to $136 \pm 0.8 \mathrm{~d}$, a total of 507 genes were altered significantly $(P<0.05$; Figure 1a). Of these 507 genes, 213 genes were further changed after delivery (between $136 \pm 0.8 \mathrm{~d}$ gestation age fetuses and newborn lambs) (Figure 1a). Similarly, in aorta 680 genes were altered significantly between $97 \pm 0$ and $136 \pm 0.8 \mathrm{~d}$ gestation age fetuses $(P<0.05$; Figure $1 \mathbf{b})$, and 173 of these were further changed following delivery (Figure 1b).

Among the 213 genes that changed significantly in the DA during both developmental transitions (from $97 \pm 0$ to $136 \pm 0.8 \mathrm{~d}$ gestation, and from $136 \pm 0.8 \mathrm{~d}$ gestation to newborn), 102 genes were altered $(>1.5$-fold; $P$ value $<0.05)$ only in the DA but not in aorta (Figure 1c). Of these 102 genes, 93 correspond to known proteins (13 genes produce proteins localizing to the extracellular space, 16 genes produce proteins localizing to the plasma membrane, 30 genes produce proteins localizing to the cytoplasmic region, and 34 genes produce proteins localizing to the nucleus). Table 1 lists the top genes, which were exclusively altered (>twofold; $P$ value $<0.05$ ) in DA but not in aorta. We conducted real-time PCR to confirm the validity of the microarray by reexamining the mRNA expression levels of desmin, fibrinogen-like 2, fatty acid binding protein 4, serum amyloid A1, hairless homolog, basic helixloop-helix family member e41, kelch domain containing 10, tumor necrosis factor receptor superfamily, member $13 \mathrm{c}$, cell division cycle associated 7, paternally expressed 10 , paternally expressed 3, and NIK related kinase. These are the top six upregulated and top six downregulated genes (Table 1). The expression levels were found to be highly correlated to the fold changes observed by microarray analysis.

\section{Pathway Analysis on Altered Genes in DA With Maturation}

We conducted Ingenuity Pathway Analysis on the 102 genes that were altered, specifically in the DA (and not in the aorta) during both developmental transitions. Figures 2 and 3 demonstrate the chief canonical and functional pathways, respectively, that are represented by the DA specific genes.

\section{Network Analysis of Altered Genes}

Using Ingenuity Pathway Analysis, we next examined the relationship between each of the DA specific gene, altered during both developmental transitions, with the other genes that were altered during the transitions. A network of direct and indirect interrelations among genes is shown Figure 4. a

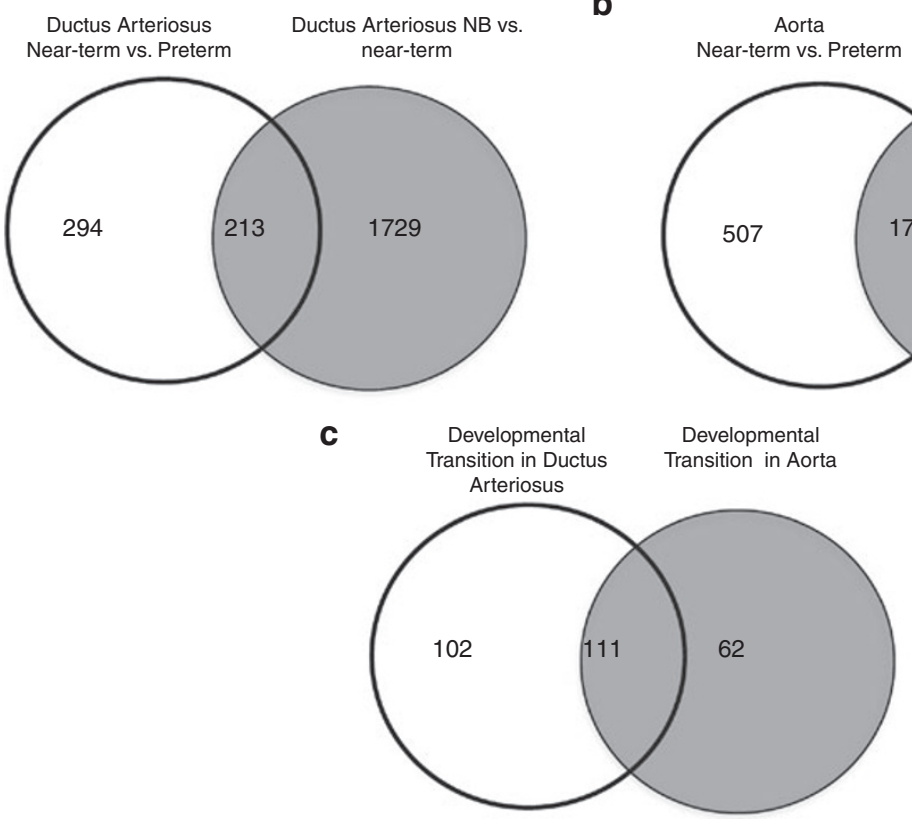

Figure 1. Venn diagram demonstrating differentially expressed genes in ovine ductus arteriousus. (a) Near-term vs. preterm and newborn (NB) vs. nearterm ductus arteriosus; (b) near-term vs. preterm and NB vs. near-term aorta; and (c) ductus and aorta with developmental transition from $97 \pm 0 \mathrm{~d}$ fetus to $136 \pm 0.8 \mathrm{~d}$ fetus, and NB lambs. The genes included are those which showed $>1.5$-fold change in expression. $N=4$ in each group; $P<0.05$. 


\section{Articles | Goyal et al.}

Table 1. Genes altered more than twofold in ductus arteriosus (not in aorta) in response to developmental transition.

\begin{tabular}{|c|c|c|c|}
\hline Gene symbol & & $136 d / 97 d$ & $\mathrm{NB} / 136 \mathrm{~d}$ \\
\hline DES & Desmin & 7.61 & 2.71 \\
\hline FGL2 & Fibrinogen-like 2 & 5.21 & 2.31 \\
\hline FABP4 & Fatty acid binding protein 4 & 5.05 & 4.61 \\
\hline SAA1 & Serum amyloid A1 & 4.83 & 70.79 \\
\hline $\mathrm{HR}$ & Hairless homolog & 3.92 & 5.67 \\
\hline BHLHE41 & $\begin{array}{l}\text { Basic helix-loop-helix } \\
\text { family, member e41 }\end{array}$ & 3.59 & 1.60 \\
\hline ANKRD1 & $\begin{array}{l}\text { Ankyrin repeat domain } 1 \\
\text { (cardiac muscle) }\end{array}$ & 3.54 & 4.10 \\
\hline APOC2 & Apolipoprotein C-II & 2.71 & 2.43 \\
\hline PDK4 & $\begin{array}{l}\text { Pyruvate dehydrogenase } \\
\text { kinase, isozyme } 4\end{array}$ & 2.66 & 14.94 \\
\hline TP53INP2 & $\begin{array}{l}\text { Tumor protein } \mathrm{p} 53 \\
\text { inducible nuclear protein } 2\end{array}$ & 2.57 & 2.38 \\
\hline HKR1 & $\begin{array}{l}\text { HKR1, GLI-Kruppel zinc } \\
\text { finger family member }\end{array}$ & 2.43 & 2.42 \\
\hline SMOC2 & $\begin{array}{l}\text { SPARC related modular } \\
\text { calcium binding } 2\end{array}$ & 2.39 & 2.67 \\
\hline THBS1 & Thrombospondin 1 & 2.39 & 4.11 \\
\hline LRRFIP1 & $\begin{array}{l}\text { Leucine rich repeat (in FLII) } \\
\text { interacting protein } 1\end{array}$ & 2.34 & 2.99 \\
\hline MAOA & Monoamine oxidase A & 2.24 & 2.70 \\
\hline GSTENG00015013001 & $\begin{array}{l}\text { Shotgun Sequence } \\
\text { SCAF14542 }\end{array}$ & 2.21 & 2.51 \\
\hline MT1A & Metallothionein $1 \mathrm{~A}$ & 2.18 & 221.19 \\
\hline RAMP1 & $\begin{array}{l}\text { Receptor } \\
\text { (G protein-coupled) } \\
\text { activity modifying } \\
\text { protein } 1\end{array}$ & 2.17 & 1.78 \\
\hline TRIB1 & Tribbles homolog 1 & 2.16 & 2.31 \\
\hline SAMD4A & $\begin{array}{l}\text { Sterile alpha motif } \\
\text { domain containing } 4 \mathrm{~A}\end{array}$ & 2.15 & 1.56 \\
\hline CD9 & CD9 molecule & 2.14 & 1.52 \\
\hline JUN & Jun proto-oncogene & 2.13 & 0.20 \\
\hline BHLHE40 & $\begin{array}{l}\text { Basic helix-loop-helix } \\
\text { family, member e40 }\end{array}$ & 2.11 & 9.81 \\
\hline TL & $\begin{array}{l}\text { Transcribed Locus } \\
\text { (unknown protein) }\end{array}$ & 2.11 & 1.96 \\
\hline MT2A & Metallothionein $2 \mathrm{~A}$ & 2.04 & 32.49 \\
\hline TMOD1 & Tropomodulin 1 & 2.00 & 2.21 \\
\hline KLHDC10 & $\begin{array}{l}\text { Kelch domain } \\
\text { containing } 10\end{array}$ & 0.49 & 0.56 \\
\hline TNFRSF13C & $\begin{array}{l}\text { Tumor necrosis factor } \\
\text { receptor superfamily, } \\
\text { member } 13 C\end{array}$ & 0.49 & 0.49 \\
\hline CDCA7 & $\begin{array}{l}\text { Cell division cycle } \\
\text { associated } 7\end{array}$ & 0.49 & 0.45 \\
\hline PEG10 & Paternally expressed 10 & 0.49 & 0.55 \\
\hline PEG3 & Paternally expressed 3 & 0.43 & 0.55 \\
\hline NRK & NIK related kinase & 0.40 & 0.20 \\
\hline RPS24 & Ribosomal protein S24 & 0.32 & 0.52 \\
\hline CTHRC1 & $\begin{array}{l}\text { Collagen triple helix repeat } \\
\text { containing } 1\end{array}$ & 0.32 & 0.08 \\
\hline
\end{tabular}

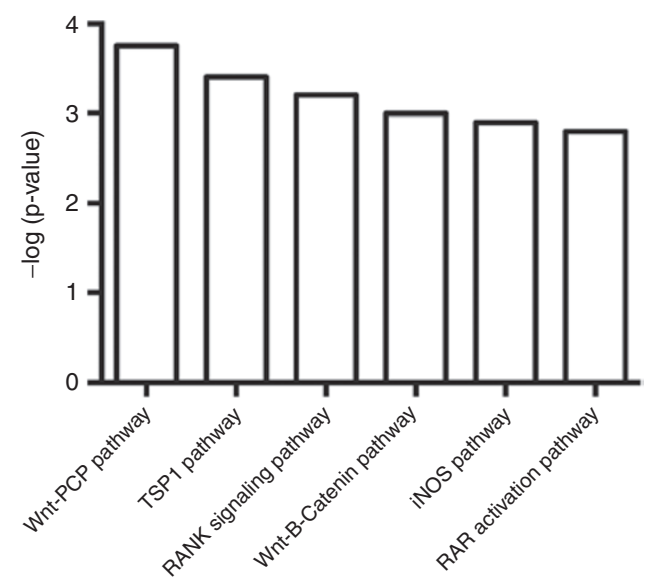

Figure 2. Bar graphs demonstrate chief canonical pathways represented by the genes altered with maturation specifically in ductus arteriosus. The genes included are those which showed $>1.5$-fold change in expression. $N=4$ in each group; $P<0.05$.

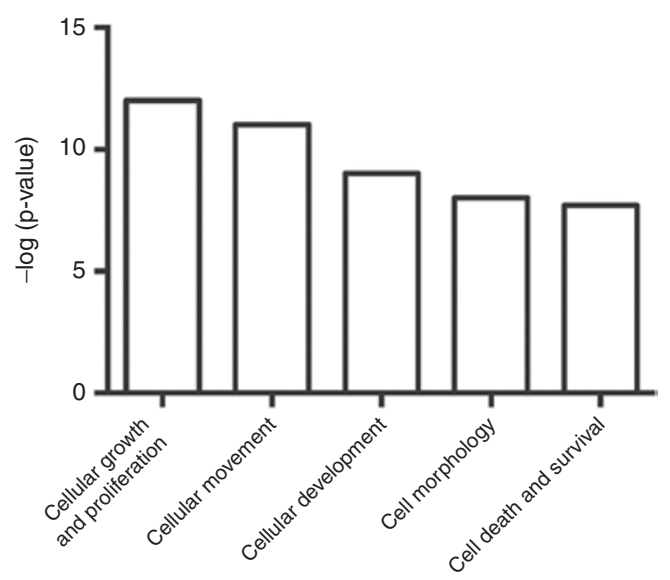

Figure 3. Bar graphs demonstrate chief functional pathways represented by the genes altered during both developmental transitions (from $97 \pm 0$ to $136 \pm 0.8 \mathrm{~d}$ gestation, and from $136 \pm 0.8 \mathrm{~d}$ gestation to newborn), specifically in ductus arteriosus. The genes included are those which showed $>1.5$-fold change in expression. $N=4$ in each group; $P<0.05$.

\section{Upstream Regulator Analysis}

The upstream regulator analysis identified several molecules, which can produce similar changes in gene expression as observed during the developmental transitions in the DA. Some of the molecules were HIF1A, interleukin 1B, interleukin 2, and p38 MAPK inhibitor SB203580. A complete list is provided in Table 2.

\section{Gene Annotation Based on Function}

Next, we annotated the genes based on known function and cellular location. Among the main downregulated genes, were 2 cytokines, 12 transcriptional regulators, 4 extracellular ligands, and 8 membrane receptor components (Table 3). Similarly, upregulated genes contained 1 ion channel, a G protein-coupled receptor, 10 transcription factors, and 6 genes which participate in cell division (Table 4). 


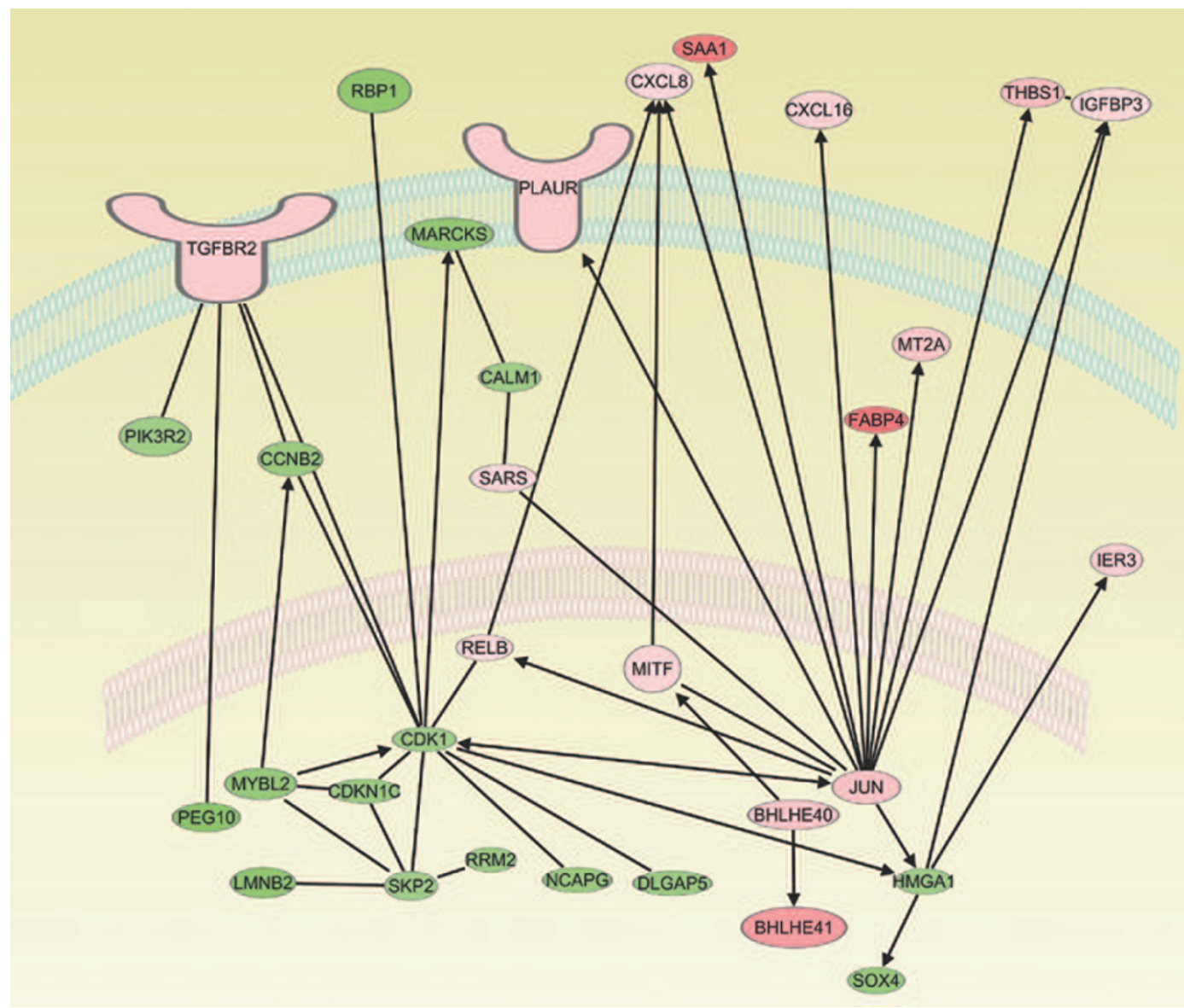

Figure 4. Network of genes represented by the genes altered during both developmental transitions, specifically in ductus arteriosus. The genes included are those which showed $>1.5$-fold change in expression. $N=4$ in each group; $P<0.05$.

\section{DISCUSSION}

The DA continues to present significant challenges to preterm infants when it fails to close after birth. In this study, we identified several candidate genes that may be important in DA maturation, as they are altered during both fetal development and postnatal closure. To our knowledge, this is the first study to examine and compare the transcriptome of both DA and aorta in premature, near-term, and newborn sheep. Several transcriptomic studies have been reported previously in mice and rats; however, these have had different experimental designs or utilized single developmental time points for comparison, thereby limiting their ability to identify genes whose developmental changes are unique to the DA (2-6). A study in the rat examined changes in gene expression between DA and aorta at day 19 and 21 (3). We reanalyzed the microarray data from this study and compared it with the present study. We observed that 13 genes were commonly altered with maturation of only DA (not in aorta) in both this study and the study in rats (Table 5). A few of the top genes which were upregulated in both of these studies were phosphodiesterase 4B (PDE4B), desmin, pyruvate dehydrogenase kinase isozyme 4 (PDK4), and insulin-like growth factor binding protein 3 (IGFBP3). The downregulated genes were cyclin-dependent kinase inhibitor $1 \mathrm{C}(\mathrm{CDKN} 1 \mathrm{C})$ and alpha-2-glycoprotein 1 (AZGP1). PDE4B limits the accumulation of cyclic AMP, which minimizes the vasodilating effects of endogenous prostaglandins within the ductus. An increase in PDE4B would facilitate DA constriction. Desmin is a marker of muscle cells and is an important cytoskeleton component. An increase in desmin with maturation may indicate a maturational increase in smooth muscle cells in the DA wall. PDK4 is known to regulate cell proliferation and apoptosis and may be important for DA closure (7). Furthermore, in our study, we observed an increase in transforming growth factor $\beta$-receptor II (TGFBR2). TGFB is known to regulate PDK4 (8) and may play an important role in DA closure and remodeling (9).

Another interesting observation in this and other studies is the increased expression of IGFBP3. IGFBP3 overexpression is well known for induction of apoptosis (10-12). Apoptosis is an integral part of DA closure following birth, and these genes could play an important role in this process. Evidence also suggests that IGFBP3 is a downstream regulator of the winglessintegrin1 (Wnt) pathway. Based on our pathway analysis, the Wnt pathway appears to play a major role in DA (but not in the aorta) development and closure. Both canonical Wnt- $\beta$ catenin as well as the Wnt-PCP signaling pathway appear to be important in DA developmental transitions. A study in mice demonstrated that increased $\beta$-catenin can lead to increased cyclooxygenase 2 and can lead to PDA (13). Cyclooxygenase 
Table 2. Chief upstream regulators which are known to produce similar gene expression changes as observed in the present dataset

\begin{tabular}{|c|c|c|c|c|c|}
\hline Upstream regulator & Molecule type & $\begin{array}{l}\text { Predicted } \\
\text { activation } \\
\text { state }\end{array}$ & $\begin{array}{l}\text { Activation } \\
z \text {-score }\end{array}$ & $\begin{array}{l}P \text { value of } \\
\text { overlap }\end{array}$ & Target molecules in dataset \\
\hline CD40LG & Cytokine & Activated & 2.2 & 1.09E-03 & CXCL8, JUN, MARCKS, MT2A, PLAUR, RELB, TNFRSF13C \\
\hline CEBPA & Transcription regulator & Activated & 2.6 & $1.26 \mathrm{E}-07$ & $\begin{array}{l}\text { CCNB2, CHI3L1, CXCL8, FABP4, HMGA1, IER3, IGFBP3, JUN, MT2A, } \\
\text { MYBL2, SAA1, TRIB1 }\end{array}$ \\
\hline CTNNB1 & Transcription regulator & Activated & 2.0 & 4.27E-06 & $\begin{array}{l}\text { BHLHE40, CALM1, CTHRC1, CXCL8, FABP4, JUN, MITF, PDE4B, PLAUR, } \\
\text { SAA1, SFRP4, SOX4 }\end{array}$ \\
\hline EDN1 & Cytokine & Activated & 2.4 & $1.41 \mathrm{E}-04$ & CDK1, CXCL8, JUN, MITF, PLAUR, THBS1 \\
\hline FOS & Transcription regulator & Activated & 2.4 & $1.58 \mathrm{E}-06$ & $\begin{array}{l}\text { CHI3L1, CXCL16, CXCL8, FABP4, JUN, MAOA, MT1A, MT2A, PLAUR, } \\
\text { RBP1, RPS24, SFRP4 }\end{array}$ \\
\hline IL2 & Cytokine & Activated & 2.2 & $4.34 \mathrm{E}-03$ & BHLHE40, CDKN1C, CXCL8, IER3, JUN, PDE4B, TNFRSF13C \\
\hline L-triiodothyronine & Chemical drug & Activated & 2.2 & $1.33 \mathrm{E}-02$ & APOC2, FABP4, HR, IGFBP3, PDK4 \\
\hline Lipopolysaccharide & Chemical drug & Activated & 2.1 & $2.01 \mathrm{E}-10$ & $\begin{array}{l}\text { APOC2, AZGP1, CALM1, CCNB2, CD53, CD9, CHI3L1, CXCL16, CXCL8, } \\
\text { FABP4, HMGA1, IER3, IGFBP3, JUN, KCNAB2, LRRFIP1, MARCKS, MT2A, } \\
\text { MYBL2, PDE4B, PDK4, PLAUR, RELB, SAA1, THBS1, TRIB1, UNC119 }\end{array}$ \\
\hline Methylprednisolone & Chemical drug & Activated & 2.2 & $2.29 \mathrm{E}-02$ & CD9, FGL2, JUN, KCNAB2, PLAUR, TYRO3 \\
\hline NUPR1 & Transcription regulator & Activated & 2.4 & $1.81 \mathrm{E}-02$ & CCNB2, CXCL8, RELB, SAMD4A, SKP2, TRIB1 \\
\hline P38 MAPK & Group & Activated & 2.5 & $6.11 \mathrm{E}-05$ & CXCL8, DES, JUN, MITF, PLAUR, RBP1, THBS1, TRIB1 \\
\hline Paclitaxel & Chemical drug & Activated & 2.6 & $1.41 \mathrm{E}-09$ & $\begin{array}{l}\text { BHLHE40, BHLHE41, CD53, CXCL8, IER3, IGFBP3, JUN, LCP1, NNAT, } \\
\text { PLAUR, TGFBR2, THBS1 }\end{array}$ \\
\hline MYC & Transcription regulator & Inhibited & -3.0 & $2.72 \mathrm{E}-09$ & $\begin{array}{l}\text { ACSL4, CCNB2, CD9, CDCA7, CDK1, CXCL8, FABP4, HMGA1, IER3, JUN, } \\
\text { MITF, PEG3, PLAUR, RBP1, RRM2, SKP2, TGFBR2, THBS1, TYMS, UNC119 }\end{array}$ \\
\hline NR3C1 & $\begin{array}{l}\text { Ligand-dependent } \\
\text { nuclear receptor }\end{array}$ & Inhibited & -2.6 & $1.29 \mathrm{E}-05$ & $\begin{array}{l}\text { BHLHE40, CDKN1C, CXCL8, IER3, JUN, MAOA, MYOC, PDE4B, RERE, } \\
\text { SOX4, THBS1, ZNF704 }\end{array}$ \\
\hline SB203580 & $\begin{array}{l}\text { Chemical kinase } \\
\text { inhibitor }\end{array}$ & Inhibited & -2.7 & 8.54E-05 & CXCL8, IER3, IGFBP3, JUN, MITF, PDE4B, PLAUR, THBS1 \\
\hline
\end{tabular}

inhibitors such as indomethacin and ibuprofen are presently used to close the PDA in preterm newborn. Moreover, $\beta$-catenin also can induce the expression of Ptgs2 (which encodes cyclooxygenase-2) and stabilize its mRNA by interacting with AU-rich elements of the 3-un-translated region $(14,15)$.

After delivery, macrophages play a crucial role in orchestrating cell death and remodeling of the newborn DA (16). Recent studies in similar vessels that undergo programmed cell death and remodeling during embryonic and fetal life have shown that this apoptotic process is mediated by macrophages via Wnt pathway (17). Of interest, the only G protein-coupled receptor altered (downregulated) with maturation specifically in ductus was frizzled class 2 receptor (FZD2). FZD2 is receptor for Wnt proteins and its activation leads to $\beta$-catenin accumulation. Thus, downregulation of FZD2 may be critical for ductus maturation and closure. However, a direct role of Wnt- $\beta$-catenin pathways in PDA closure remains to be evaluated by pharmacological agents.

Other than the Wnt pathway, this study identified several canonical pathways, which were altered significantly with developmental transitions in DA, but not in aorta. The top of the list included thrombospondin 1, receptor activator of nuclear factor-kappa B, nitric oxide synthase (NOS), and retinoic acid receptor (RAR) activation signaling pathways. Of these, there is substantial evidence for the involvement of retinoic acid pathway in DA maturation. In a transgenic mice 
Table 3. Functional annotation of the downregulated genes with ductus arteriosus developmental transition

\begin{tabular}{|c|c|c|}
\hline Symbol & Entrez gene name & Type(s) \\
\hline SKA1 & Spindle and kinetochore associated complex subunit 1 & Cell division \\
\hline ZWINT & ZW10 interacting kinetochore protein & Cell division \\
\hline KNTC1 & Kinetochore associated 1 & Cell division \\
\hline NCAPG & Non-SMC condensin I complex, subunit G & Cell division \\
\hline CENPH & Centromere protein $\mathrm{H}$ & Cell division \\
\hline CCNB2 & Cyclin B2 & Cell division \\
\hline RRM2 & Ribonucleotide reductase M2 & Enzyme \\
\hline RAD54L & RAD54-like (S. cerevisiae) & Enzyme \\
\hline NDUFA2 & NADH dehydrogenase (ubiquinone) 1 alpha subcomplex, 2, 8 kDa & Enzyme \\
\hline CA11 & Carbonic anhydrase XI & Enzyme \\
\hline RASL11B & RAS-like, family 11 , member $B$ & Enzyme \\
\hline KCNAB2 & Potassium voltage-gated channel, shaker-related subfamily, beta member 2 & lon channel \\
\hline CDK1 & Cyclin-dependent kinase 1 & Kinase \\
\hline PIK3R2 & Phosphoinositide-3-kinase, regulatory subunit 2 (beta) & Kinase \\
\hline TYRO3 & TYRO3 protein tyrosine kinase & Kinase \\
\hline TRIO & Trio Rho guanine nucleotide exchange factor & Kinase \\
\hline NRK & NIK related kinase & Kinase \\
\hline CDKN1C & Cyclin-dependent kinase inhibitor 1C (p57, Kip2) & Kinase regulator \\
\hline DLGAP5 & Discs, large (Drosophila) homolog-associated protein 5 & Phosphatase \\
\hline UNC119 & Unc-119 homolog (C. elegans) & Protein trafficking \\
\hline PTGFRN & Prostaglandin F2 receptor inhibitor & Receptor regulator \\
\hline MARCKS & Myristoylated alanine-rich protein kinase $C$ substrate & Structural protein \\
\hline LMNB2 & Lamin B2 & Structural protein \\
\hline CTHRC1 & Collagen triple helix repeat containing 1 & Structural protein \\
\hline HMGA1 & High mobility group AT-hook 1 & Transcription regulator \\
\hline ZNF704 & Zinc finger protein 704 & Transcription regulator \\
\hline HMGN1 & High mobility group nucleosome binding domain 1 & Transcription regulator \\
\hline ZNF532 & Zinc finger protein 532 & Transcription regulator \\
\hline SOX4 & SRY (sex determining region $\mathrm{Y}$ )-box 4 & Transcription regulator \\
\hline MYBL2 & v-myb avian myeloblastosis viral oncogene homolog-like 2 & Transcription regulator \\
\hline ASF1B & Anti-silencing function $1 \mathrm{~B}$ histone chaperone & Transcription regulator \\
\hline CDCA7 & Cell division cycle associated 7 & Transcription regulator \\
\hline PEG10 & Paternally expressed 10 & Transcription regulator \\
\hline PEG3 & Paternally expressed 3 & Transcription regulator \\
\hline RPS24 & Ribosomal protein S24 & Translational regulator \\
\hline SFRP4 & Secreted frizzled-related protein 4 & Transmembrane receptor \\
\hline TNFRSF13C & Tumor necrosis factor receptor superfamily, member $13 \mathrm{C}$ & Transmembrane receptor \\
\hline SLC2A8 & Solute carrier family 2 (facilitated glucose transporter), member 8 & Transporter \\
\hline AZGP1 & Alpha-2-glycoprotein 1, zinc-binding & Transporter \\
\hline RBP1 & Retinol binding protein 1, cellular & Transporter \\
\hline
\end{tabular}




\section{Articles $\mid$ Goyaletal.}

Table 4. Functional annotations of the upregualted genes with ductus arteriosus developmental transition

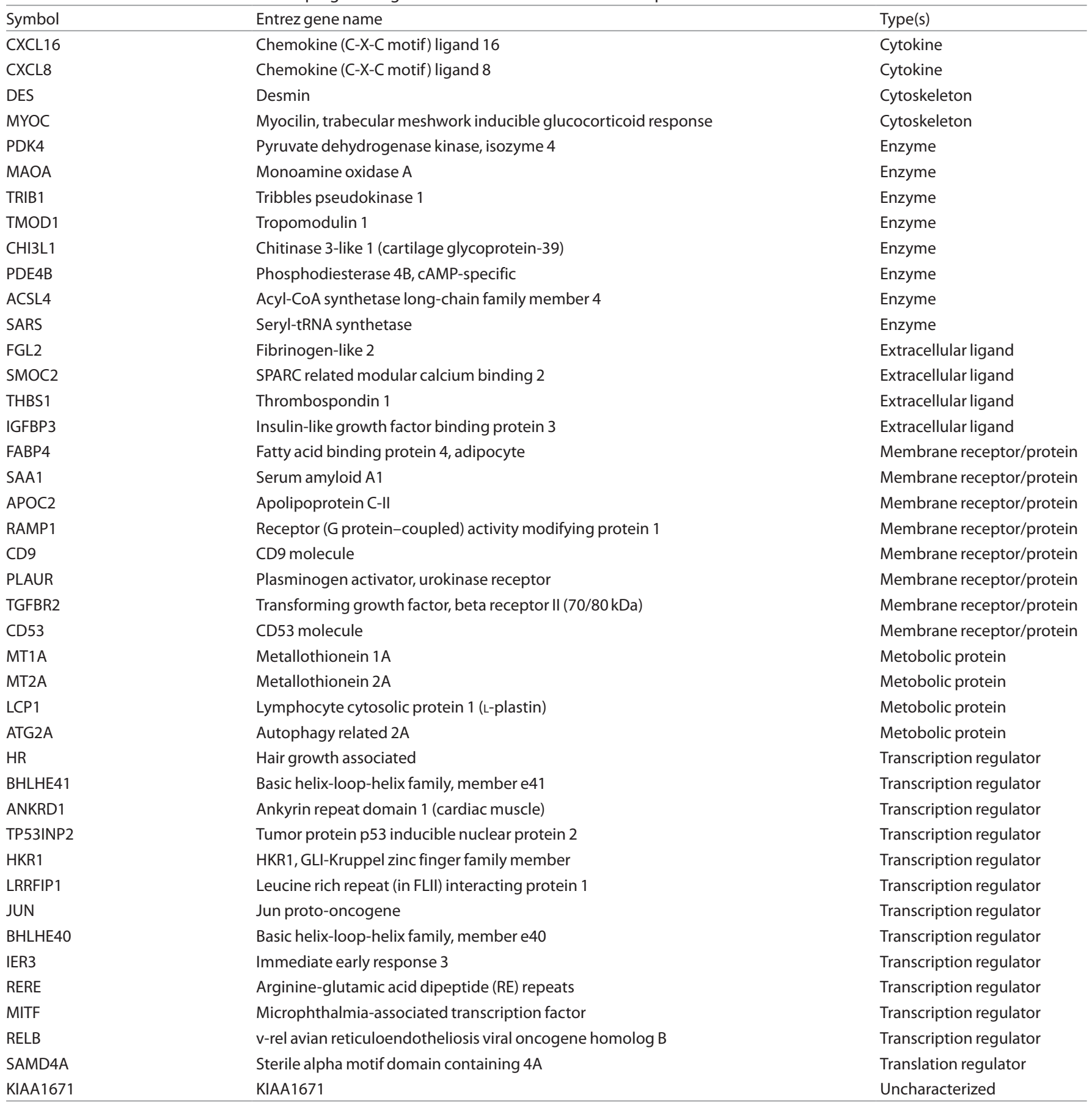

study, intense activation of retinoic acid signaling was detected in DA during in-utero development (18). Importantly, such activation was absent in adjacent aortic or pulmonary arterial segments (18). Similarly, several other studies support the role of RAR in DA closure (19-21). However, further investigation is needed to determine the therapeutic potential of these pathways for treating PDA.

In this study, we observed upregulation of two cytokines: chemokine ligand 16 (CXCL16) and 8 (CXCL8). Notably, CXCL8 levels are known to be regulated by oxygen therapy in preterm infants (22). In addition, we observed upregulation of a number of transcription factors whose roles need to be evaluated. Similarly, we observed downregulation of several genes involved in cell division.

\section{Perspective and Conclusion}

Despite decades of research noninvasive options for closing a PDA remain limited. Accumulating evidence from microarray studies suggest that several genes and pathways involved with transcriptional regulation may have a unique role in the developmental transitions and closure of DA. A direct role of these pathways in DA closure needs to be demonstrated in future 
Table 5. Genes common in this study and a study in rat ductus

\begin{tabular}{llcc}
\hline Gene symbol & & $136 \mathrm{~d} / 97 \mathrm{~d}$ & Rat DA21/DA19 \\
\hline DES & Desmin & 7.61 & 4.13773421 \\
PDK4 & $\begin{array}{l}\text { Pyruvate dehydrogenase } \\
\text { kinase, isozyme 4 }\end{array}$ & 2.66 & 2.566222222 \\
& Monoamine oxidase A & 2.24 & 2.175630978 \\
MAOA & CD9 molecule & 2.14 & 1.525717393 \\
CD9 & Jun proto-oncogene & 2.13 & 2.888589354 \\
JUN & $\begin{array}{l}\text { Basic helix-loop-helix family, } \\
\text { member e40 }\end{array}$ & 2.11 & 1.522832723 \\
BHLHE40 & & \\
& Immediate early response 3 & 1.79 & 1.726213221 \\
IER3 & $\begin{array}{l}\text { Phosphodiesterase 4B, } \\
\text { PDE4B }\end{array}$ & 1.70 & 2.505808477 \\
ACSL4 & $\begin{array}{l}\text { Acyl-CoA synthetase long- } \\
\text { chain family member 4 }\end{array}$ & 1.57 & 1.657947377 \\
IGFBP3 & $\begin{array}{l}\text { Insulin-like growth factor } \\
\text { binding protein 3 }\end{array}$ & 1.52 & 1.579121148 \\
& $\begin{array}{l}\text { Cyclin-dependent kinase } \\
\text { inhibitor 1C (p57, Kip2) }\end{array}$ & 0.61 & 0.407179049 \\
CDKN1C & $\begin{array}{l}\text { Alpha-2-glycoprotein 1, } \\
\text { zinc-binding }\end{array}$ & 0.60 & 0.507969152 \\
AZGP1 & & & \\
\hline
\end{tabular}

studies using pharmacological agents that can regulate these pathways. Fortunately, well-established pharmacological modulators are available for several of these pathways. This study provides support for experimental intervention that targets the Wnt and RAR, and perhaps other signaling pathways to determine their therapeutic potential for treating the PDA.

\section{METHODS}

\section{Experimental Animals and Tissues}

All experimental procedures were performed within the regulations of the Animal Welfare Act, the National Institutes of Health Guide for the Care and Use of Laboratory Animals, the Guidelines of the American Physiological Society and were approved by the Animal Care and Use Committee of Loma Linda University and the University of California, San Francisco.

We isolated DA and a segment of ascending aorta from preterm $(97 \pm 0 \mathrm{~d}$ gestation) and near-term $(136 \pm 0.8 \mathrm{~d})$ fetal sheep (full term $=145 \mathrm{~d}$ ) and from $12 \pm 0 \mathrm{~h}$ old newborn lambs (obtained from Pozzi Ranch, Valley Ford, CA). Four animals $(n=4)$ were used for each experimental group. At the time of experimental study, ewes and newborn lambs were killed with an overdose of the proprietary euthanasia solution, Euthasol (pentobarbital sodium $100 \mathrm{mg} / \mathrm{kg}$ and phenytoin sodium $10 \mathrm{mg} / \mathrm{kg}$; Virbac, Ft. Worth, TX).

\section{Tissue Collection and Microarray Processing}

In previous studies, we have described this technique in detail (23-25). Microarray analysis was conducted by utilizing the commercial services of GenUs BioSystems (Northbrook, IL). Briefly, DA and aorta segments (adjacent to DA) were homogenized and lysed in Trizol (Ambion, Austin, TX), and total RNA was isolated using phenol/chloroform extraction followed by purification over spin columns (Ambion). Total RNA concentration and purity of total RNA were measured by spectrophotometry at $\mathrm{OD}_{2601280}$, and the quality of the total RNA sample was assessed using an Agilent Bioanalyzer (see Supplementary Figure S1 online) with RNA 6000 Nano Lab Chip (Agilent Technologies, Santa Clara, CA).

Labeled cRNA was prepared by linear amplification of the Poly(A) + RNA population within the total RNA sample. Briefly, $<1 \mu \mathrm{g}$ of total RNA was reverse transcribed after priming with a DNA oligonucleotide containing the T7 RNA polymerase promoter $5^{\prime}$ to a d(T)24 sequence. Following second-strand cDNA synthesis and purification of double-stranded CDNA, in vitro transcription was performed using T7 RNA polymerase. The quantity and quality of the labeled cRNA were assayed by spectrophotometry and Agilent Bioanalyzer.

One microgram of purified cRNA was fragmented to uniform size and applied to Agilent Sheep Gene Expression Microarray, $8 \times 15 \mathrm{~K}$ (Design ID 019921, Agilent Technologies) in hybridization buffer. The arrays were hybridized at $65^{\circ} \mathrm{C}$ for $17 \mathrm{~h}$ in a shaking incubator and washed at $37^{\circ} \mathrm{C}$ for $1 \mathrm{~min}$. Rinsed and dried arrays were scanned with an Agilent G2565 Microarray Scanner (Agilent Technologies) at $5 \mu \mathrm{m}$ resolution. Agilent Feature Extraction software was used to process the scanned images from arrays (gridding and feature intensity extraction), and the data generated for each probe on the array was analyzed with GeneSpring GX v7.3.1 software (Agilent Technologies). Annotations are based on the Agilent eArray annotation file dated January 2010.

\section{Pathway/Network Analysis}

The probes not annotated by the Agilent eArray annotation file were annotated manually using NCBI Blast Search, Unigene, Entrez, or other databases. We then analyzed the annotated genes using Ingenuity Pathway Analysis Program (Ingenuity Systems, Redwood City, CA).

\section{Upstream Regulator Analysis}

The goal of the upstream regulator analysis was to identify the signal transduction regulators that can mimic the observed gene expression changes in the present dataset with respect to the biological activities occurring in the tissues or cell system. Upstream regulator analysis was conducted using Ingenuity Pathway Analysis software. The direction of change in the gene expression observed in the experimental samples (relative to a control) was compared for changes in gene expression observed by application of a particular upstream regulator as published in the literature. Each potential upstream regulator was analyzed by using two statistical measures: an overlap $P$ value and an activation $z$-score $(23,26)$. The overlap $P$ value was based on significant overlap between dataset genes and known targets regulated by an upstream regulator. The activation $z$-score was used to infer activation states of upstream regulators based on comparison with a model that assigns random regulatory directions (http://ingenuity.force.com/ipa/ servlet/fileField?id=0BE50000000PDow).

\section{Real-Time PCR Validation}

Microarray analysis results were validated by real-time PCR. We chose the top six upregulated and six downregulated genes for analysis using real-time PCR. We designed primers using the same probe sequences as those on the microarray chip with the use of Primer 3 web-based software (http://frodo.wi.mit.edu/primer3/). The primers were synthesized by Integrated DNA Technologies (Coralville, CA). Total RNA (1 $\mu \mathrm{g}$ per reaction) was reverse transcribed using a QuantiTect Reverse Transcriptase Kit (Qiagen, Valencia, CA). Relative expression was normalized to $18 \mathrm{~S}$ RNA and fold-changes were calculated using the $\Delta \Delta$ cycle threshold method (27). Samples were analyzed on the LightCycler 1.5 (Roche, Indianapolis, IN).

\section{Statistics}

Individual expression values across arrays were compared by normalizing raw intensity data from each gene to the 75th percentile intensity of each array. Only genes with values greater than background intensity for all samples within each group were used for further analysis. Differentially expressed genes were identified by 1.5 -fold change and Welch $t$-test $P$ values $<0.05$ between each age and vessel group. Statistical significance in the real-time PCR data was determined by one-way ANOVA and post-hoc Newman-Keuls test.

\section{SUPPLEMENTARY MATERIAL}

Supplementary material is linked to the online version of the paper at http:// www.nature.com/pr

\section{STATEMENT OF FINANCIAL SUPPORT}

This work was supported by grants from National Institute of Health, Bethesda, MD (HL109199 and HL46691 to R.I.C. and HD03807 to R.G.) and a gift from the Jamie and Bobby Gates Foundation, San Francisco, CA. 


\section{Articles Goyaletal.}

\section{REFERENCES}

1. Clyman RI. Mechanisms regulating closure of the ductus arteriosus. In: Polin R, Fox W, Abman S, eds. Fetal and Neonatal Physiology. Philadelphia, PA:W.B. Saunders Co., 2011:821-827

2. Bökenkamp R, van Brempt R, van Munsteren JC, et al. Dlx1 and Rgs5 in the ductus arteriosus: vessel-specific genes identified by transcriptional profiling of laser-capture microdissected endothelial and smooth muscle cells. PLoS One 2014;9:e86892.

3. Hsieh YT, Liu NM, Ohmori E, et al. Transcription profiles of the ductus arteriosus in Brown-Norway rats with irregular elastic fiber formation. Circ J 2014;78:1224-33.

4. Jin MH, Yokoyama U, Sato Y, et al. DNA microarray profiling identified a new role of growth hormone in vascular remodeling of rat ductus arteriosus. J Physiol Sci 2011;61:167-79.

5. Shelton EL, Ector G, Galindo CL, et al. Transcriptional profiling reveals ductus arteriosus-specific genes that regulate vascular tone. Physiol Genomics 2014;46:457-66.

6. Liu NM, Yokota T, Maekawa S, et al. Transcription profiles of endothelial cells in the rat ductus arteriosus during a perinatal period. PLoS One 2013;8:e73685.

7. Grassian AR, Metallo CM, Coloff JL, Stephanopoulos G, Brugge JS. Erk regulation of pyruvate dehydrogenase flux through PDK4 modulates cell proliferation. Genes Dev 2011;25:1716-33.

8. Sun Y, Daemen A, Hatzivassiliou G, et al. Metabolic and transcriptional profiling reveals pyruvate dehydrogenase kinase 4 as a mediator of epithelial-mesenchymal transition and drug resistance in tumor cells. Cancer Metab 2014;2:20.

9. Tannenbaum JE, Waleh NS, Mauray F, et al. Transforming growth factor beta 1 inhibits fetal lamb ductus arteriosus smooth muscle cell migration. Pediatr Res 1995;37:561-70.

10. Han JJ, Xue DW, Han QR, et al. Induction of apoptosis by IGFBP3 overexpression in hepatocellular carcinoma cells. Asian Pac J Cancer Prev 2014;15:10085-9.

11. Oikonomopoulos A, Sereti KI, Conyers F, et al. Wnt signaling exerts an antiproliferative effect on adult cardiac progenitor cells through IGFBP3. Circ Res 2011;109:1363-74.

12. Wu YC, Buckner BR, Zhu M, Cavanagh HD, Robertson DM. Elevated IGFBP3 levels in diabetic tears: a negative regulator of IGF-1 signaling in the corneal epithelium. Ocul Surf 2012;10:100-7.

13. Yajima I, Colombo S, Puig I, et al. A subpopulation of smooth muscle cells, derived from melanocyte-competent precursors, prevents patent ductus arteriosus. PLoS One 2013;8:e53183.
14. Araki Y, Okamura S, Hussain SP, et al. Regulation of cyclooxygenase-2 expression by the Wnt and ras pathways. Cancer Res 2003;63:728-34.

15. Lee HK, Jeong S. Beta-Catenin stabilizes cyclooxygenase-2 mRNA by interacting with AU-rich elements of $3^{\prime}$-UTR. Nucleic Acids Res 2006;34:5705-14.

16. Waleh N, Seidner S, McCurnin D, et al. Anatomic closure of the premature patent ductus arteriosus: the role of CD14+/CD163+ mononuclear cells and VEGF in neointimal mound formation. Pediatr Res 2011;70:332-8.

17. Kurihara T, Kubota Y, Ozawa Y, et al. von Hippel-Lindau protein regulates transition from the fetal to the adult circulatory system in retina. Development 2010;137:1563-71.

18. Colbert MC, Kirby ML, Robbins J. Endogenous retinoic acid signaling colocalizes with advanced expression of the adult smooth muscle myosin heavy chain isoform during development of the ductus arteriosus. Circ Res 1996;78:790-8.

19. Momma K, Toyono M, Miyagawa-Tomita S. Accelerated maturation of fetal ductus arteriosus by maternally administered vitamin A in rats. Pediatr Res 1998;43:629-32.

20. Wu GR, Jing S, Momma K, Nakanishi T. The effect of vitamin A on contraction of the ductus arteriosus in fetal rat. Pediatr Res 2001;49: 747-54.

21. Wu LH, Xu SJ, Teng JY, Wu W, Ye DY, Wu XZ. Differential response of human fetal smooth muscle cells from arterial duct to retinoid acid. Acta Pharmacol Sin 2008;29:413-20.

22. De Dooy J, Ieven M, Stevens W, De Clerck L, Mahieu L. High levels of CXCL8 in tracheal aspirate samples taken at birth are associated with adverse respiratory outcome only in preterm infants younger than 28 weeks gestation. Pediatr Pulmonol 2007;42:193-203.

23. Goyal R, Longo LD. Acclimatization to long-term hypoxia: gene expression in ovine carotid arteries. Physiol Genomics 2014;46:725-34.

24. Goyal R, Longo LD. Gene expression in sheep carotid arteries: major changes with maturational development. Pediatr Res 2012;72: 137-46.

25. Goyal R, Van Wickle J, Goyal D, Matei N, Longo LD. Antenatal maternal long-term hypoxia: acclimatization responses with altered gene expression in ovine fetal carotid arteries. PLoS One 2013;8:e82200.

26. Dobyns AE, Goyal R, Carpenter LG, Freeman TC, Longo LD, Yellon SM. Macrophage gene expression associated with remodeling of the prepartum rat cervix: microarray and pathway analyses. PLoS One 2015;10:e0119782.

27. Pfaffl MW. A new mathematical model for relative quantification in realtime RT-PCR. Nucleic Acids Res 2001;29:2002-2007. 